\title{
ANALISIS POTENSI EKONOMI KABUPATEN MINAHASA SELATAN
}

\author{
Feybi Hadjarati \\ Juliana R. Mandei \\ Ribka M. Kumaat
}

\begin{abstract}
The problem in this research is the in the basic sector in South Minahasa District and the potential sectors to be developed as a support for economic growth in South Minahasa District. The purpose of this study is to analyze the basic sector and potential sectors in South Minahasa district. The study lasted four months starting June 2016 until September 2016, started with the preparation period to the preparation of research studies. This study used secondary data obtained from the Central Bureau of Statistics of North Sulawesi province and the Central Bureau of Statistics South Minahasa district. Analysis used LQ, Shift Share, and MRP. The Result shows that the base sector in the Domestic Regional Product Of South Minahasa District. There are four sectors Agriculture sector, Mining and Quarrying, Manufacturing Industry Sector, and the Construction Sector. Values shift share South Minahasa district likely to lead to an economy that will grow relatively slowly and did not have a competitive advantage, and There are two sectors of the value of MRP that stand out in North Sulawesi province and South Minahasa District the Construction Sector, and Health Services and Social Activity sectors. Manufacturing sector, and Administration Sector, Government, Defense and Compulsory Social Assurance. These sectors are expected to be a potential role in contributing to the growth in north Sulawesi province because These sectors are potential sector that can be developed in South Minahasa district.
\end{abstract}

Key words:economic potential,basic sector, potential sectors, South Minahasa

\begin{abstract}
ABSTRAK
Masalah dalam penelitian ini adalah sektor - sektor apa yang menjadi basis di Kabupaten Minahasa Selatan dan sektor-sektor yang potensial untuk di kembangkan sebagai penunjang pertumbuhan ekonomi di Kabupaten Minahasa Selatan. Tujuan penelitian ini yaitu menganalisis sektor basis dan sektor potensial di Kabupaten Minahasa Selatan. Penelitian ini berlangsung selama 4 bulan mulai bulan Juni 2016 sampai dengan bulan September 2016, mulai dari masa persiapan penelitian sampai dengan penyusunan hasil penelitian. penelitian ini menggunakan data sekunder yang di peroleh dari Badan Pusat Statistik Provinsi Sulawesi Utara dan Badan Pusat Statistik Kabupaten Minahasa Selatan. Analisis menggunakan LQ, Shift Share, dan MRP. Hasil Penelitian menunjukan bahwa Sektor Basis dalam PDRB Kabupaten Minahasa Selatan terdapat empat sektor yakni Sektor Pertanian, Sektor Pertambangan dan Penggalian, Sektor Industri Pengolahan, dan Sektor Konstruksi. Nilai shift share Kabupaten Minahasa Selatan cenderung mengarah pada perekonomian yang tumbuh relatif lambat dan sama sekali tidak memiliki keunggulan kompetitif dan untuk nilai MRP terdapat dua sektor yang menonjol di Provinsi Sulawesi Utara maupun di Kabupaten Minahasa Selatan yakni Sektor Konstruksi dan Sektor Jasa Kesehatan dan Kegiatan Sosial. kemudian Sektor Industri Pengolahan dan Sektor Administrasi, Pemerintahan, Pertahanan, dan Jaminan Sosial Wajib, Sektor ini di harapkan akan potensial peranannya dalam memberikan kontribusi pertumbuhan di provinsi Sulawesi utara sebab sektor ini merupakan sektor potensial yang dapat di kembangkan di Kabupaten Minahasa Selatan.
\end{abstract}

Kata kunci: potensi ekonomi, sektor basis, sektor potensial, Minahasa Selatan 


\section{PENDAHULUAN}

\section{Latar Belakang}

Pembangunan nasional di negara-negara berkembang pada umumnya, terfokus pada pembangunan ekonomi melalui usaha pertumbuhan ekonomi. Pertumbuhan ekonomi berkaitan erat dengan peningkatan produksi barang dan jasa yang diukur antara lain melalui Produk Domestik Bruto ( PDB ) pada tingkat nasional dan Produk Domestik Regional Bruto ( PDRB) pada tingkat daerah baik Provinsi, Kabupaten maupun Kota. Pelaksanaan pembangunan Indonesia selama ini juga tidak terlepas dari pandangan tersebut. Indonesia sebagai suatu negara kesatuan, rencana pembangunannya meliputi rencana pembagunan nasional maupun rencana pembangunan dalam tataran regional. (Soeparmoko, 2002)

Makin tinggi PDRB suatu daerah maka ini bisa berarti tingkat kegiatan perekonomian di daerah tersebut juga tinggi demikian juga sebaliknya. PDRB di Indonesia pada dasaranya terdiri dari 9 sektor atau lapangan usaha namun Mulai tahun 2015, BPS merubah tahun dasar 2000 menjadi tahun dasar 2010 dalam penghitungan PDB maupun PDRB. Perubahan tersebut merupakan rekomendasi dari Perserikatan Bangsa Bangsa (PBB) yang tertuang dalam System of National Accounts (SNA) 1993.

Seiring dengan perubahan tahun dasar tersebut, juga dilakukan implementasi SNA 2008 beralih dari SNA 1993. Perubahan-perubahan tersebut membawa sejumlah im-plikasi diantaranya naiknya nilai nominal atau level dari PDB maupun PDRB yang secara tidak langsung akan merubah nilai indikator turunan PDB maupun PDRB. Dalam penyajiannya PDRB menurut lapangan usaha mengalami perubahan klasifikasi menjadi 17 lapangan usaha. Provinsi Sulawesi Utara ialah sebuah daerah yang terletak di paling utara pulau Sulawesi.

Sulawesi Utara merupakan sebuah provinsi yang ber ibukota Manado. Provinsi Sulawesi Utara mempunyai 15 Kabupaten kota yakni Kabupaten Bolaang Mongondow, Kabupaten Bolaang Mongondow Selatan, Kabupaten Bolaang Mongondow Timur, Kabupaten Bolaang Mongondow Utara, Kabupaten Kepulauan Sangihe, Kabupaten Kepulauan Siau Tagulandang Biaro, Kabupaten Kepulauan Talaud, Kabupaten Minahasa, Kabupaten Minahasa Selatan, Kabupaten
Minahasa Tenggara, Kabupaten Minahasa Utara, Kota Bitung, Kota Kotamobagu, Kota Manado dan Kota Tomohon. Tentunya setiap Kabupaten dan Kota masing-masing mempunyai potensi ekonomi yang khas sesuai keadaan daerahnya masing-masing sehingga akan mempunyai PDRB, tingkat pertumbuhan dan prioritas sektoral yang berbeda-beda..Laju pertumbuhan ekonomi di masing-masing Kabupaten/ Kota tahun 2010-2014 terdapat empat Kabupaten yang mempunyai laju pertumbuhan ekonomi rata-rata terendah dalam kurun waktu lima tahun di bandingkan kabupaten lainnya berada di bawah $6 \%$ yaitu Kabupaten Kepulauan Talaud, Kabupaten Bolaang Mongondow, Kabupaten Kepulauan Sangihe dan Kabupaten Minahasa Selatan. Daerah yang memiliki rata-rata laju pertumbuhan rendah bukan berarti daerah tersebut tidak memiliki potensi, Terlebih khusus Kabupaten Minahasa Selatan.

Kabupaten Minahasa Selatan adalah kabupaten yang di mekarkan pada tahun 2003 dengan disahkannya Undang-Undang Nomor 10 Tahun 2003 tentang Pembentukan Kabupaten Minahasa Selatan dan Kota Tomohon di Provinsi Sulawesi Utara oleh DPR RI. Kabupaten Minahasa Selatan diresmikan oleh Menteri Dalam Negeri Harry Sabarno atas nama Presiden Republik Indonesia pada tanggal 4 Agustus 2003. Kabupaten Minahasa Selatan memiliki banyak potensi ekonomi di antaranya sektor pertanian, sektor konstruksi dan sektor industri pengolahan. Peranan setiap sektor ekonomi dalam perekonomian dapat diketahui dari angka distribusi persentase Produk Domestik Regional Bruto (PDRB). Sektor jasa perusahaan merupakan sektor ekonomi yang mempunyai peranan paling rendah dalam perekonomian Kabupaten Minahasa Selatan pada tahun 2014. Sementara itu sektor pertanian adalah sektor ekonomi yang paling besar sumbangannya dalam perekonomian Kabupaten Minahasa Selatan pada tahun 2014. Berdasarkan uraian diatas maka penelitian ini akan menganalisis tentang potensi ekonomi di Kabupaten Minahasa Selatan pada tahun 20102014. Berikut kontribusi sektoral terhadap pembentukan PDRB Kabupaten Minahasa Selatan.

\section{Rumusan Masalah}

Berdasarkan permasalahan yang telah di kemukakan, maka rumusan masalahnya sebagai 
berikut:

1.Sektor - sektor apa yang menjadi basis di Kabupaten Minahasa Selatan?

2. Sektor-sektor mana yang potensial untuk dikembangkan sebagai penunjang pertumbuhan ekonomi di Kabupaten Minahasa Selatan ?

\section{Tujuan Penelitian}

Berdasarkan latar belakang dan rumusan masalah maka tujuan penelitian ini adalah :

1. Menganalisis sektor basis dan non basis di Kabupaten Minahasa Selatan

2. Menganalisis sektor-sektor yang potensial untuk dikembangkan sebagai penunjang pertumbuhan ekonomi di kabupaten Minahasa Selatan.

\section{Manfaat Penelitian}

1. Tambahan informasi dan bahan kajian tentang gambaran/informasi tentang potensi pertumbuhan ekonomi di Kabupaten Minahasa Selatan sehingga pemerintah daerah dapat lebih mengembangkan potensi daerahnya.

2. Dapat menjadi masukan bagi para pembuat kebijakan yang berhubungan dengan pembangunan Kabupaten Minahasa Selatan dalam rangka program pembangunan selanjutnya dan tetap mempertahankan pertumbuhan ekonomi yang ada.

\section{METODOLOGI PENELITIAN}

\section{Tempat dan Waktu Penelitian}

Waktu pelaksanaan selama 4 bulan mulai bulan juni 2016 sampai dengan bulan September 2016, mulai dari masa persiapan penelitian sampai dengan penyusunan hasil penelitian. Tempat penelitian di lakukan di Kabupaten Minahasa Selatan.

\section{Metode Pengumpulan Data}

Data yang digunakan dalam penelitian ini adalah data sekunder. Data sekunder yaitu data PDRB sektor-sektor ekonomi menurut lapangan usaha di Kabupaten Minahasa Selatan Tahun 2010 sampai dengan tahun 2014 dan data PDRB sektor-sektor ekonomi menurut lapangan usaha di Provinsi Sulawesi Utara periode 2010 - 2014.

\section{Konsep Pengukuran Variabel}

1. PDRB Provinsi Sulawesi Utara tahun 20102014 ADHK tahun 2010(rupiah)

2.PDRB menurut sektor Provinsi Sulawesi Utara tahun 2010-2014 ADHK tahun 2010 (rupiah)

3.PDRB Kabupaten Minahasa Selatan tahun 2010-2014 ADHK tahun 2010 (rupiah)

4.PDRB menurut sektor Kabupaten Minahasa Selatan tahun 2010-2014 ADHK tahun 2010 (rupiah)

\section{Analisis LQ}

\section{Analisis Data}

Analisis data yang di gunakan dalam penelitian ini adalah analisis LQ. Analisis ini membandingkan besarnya peranan sektor (Kabupaten Minahasa Selatan) terhadap besarnya peranan sektor tersebut pada wilayah referensi ( Provinsi Sulawesi Utara ) rumusnya adalah sebagai berikut :

$\mathrm{LQ}=\underline{\mathrm{ei} / \mathrm{et}}$

$\mathrm{LQ}=$ indeks location quotient

$\mathrm{Ei}=$ PDRB sektor i Kabupaten Minahasa Selatan

Et = PDRB total seluruh sektor Kabupaten Minahasa Selatan

$\mathrm{Ei}=$ PDRB sektor i tingkat Provinsi Sulawesi Utara

Et = PDRB total seluruh sektor tingkat Sulawesi Utara

2. Analisis Shift Share (SS)

Analisis ini di bagi menjadi dua komponen yaitu Proportional Shift (PS) dan Differential Shift (DS). Jika komponen PS positif maka daerah yang berspasialisasi dalam sektor-sektor wilayah Sulawesi Utara mengalami pertumbuhan yang cepat dan jika komponen PS negatif maka daerah yang berspesialisasi dalam sektor-sektor wilayah Sulawesi Utara tumbuh dengan lambat. Komponen DS positif apabila suatu daerah mempunyai keuntungan lokasional seperti sumber daya yang melimpah dalam sektor industri tertentu dan di katakan negatif apabila tidak mempunyai keuntungan. Pengukuran dari analisis Shift Share (Tarigan, 2005) sebagai berikut:

a. PS menunjukkan komponen proportional shift yang dipakai untuk menghasilkan besarnya shift netto bila terjadi perubahan PDRB pada 
sector. Komponen ini positif apabila di daerah yang berspesialisasi pada sektor tertentu di Provinsi Sulawesi Utara tumbuh lebih cepat dan negatif bila daerah berspesialisasi pada sektor i dan pertumbuhannya lebih lambat.

b. DS menunjukkan differential shift yang dipakai untuk mengukur besarnya shift netto yang diakibatkan oleh sektor tertentu yang lebih cepat atau lambat pertumbuhannya di wilayah studi (Kabupaten Minahasa Selatan) karena faktor lokasional, seperti melimpahnya sumber daya dan mengukur keunggulan kompetitif sektor di daerah tersebut. $D S$ bernilai positif apabila ada sektor yang memiliki keunggulan kompetitif dan $D S$ bernilai negatif terhadap sektor yang tidak memiliki keunggulan kompetitif.

Rumus Shift Share (Tarigan, 2005) adalah: $E_{r}=E_{r, t}-E_{r, t-n}$

Artinya pertambahan sektor i adalah banyaknya jumlah output sektor i pada tahun akhir dikurangi output pada sektor i pada tahun awal. Persamaan diatas berlaku untuk total output pada sektor i di Kabupaten Minahasa Selatan. Hal ini dapat juga dilihat persektor sebagai berikut:

$P S=\left(E_{N, i, t} / E_{N, i, t-n}\right)-\left(E_{N, t} / E_{N, t-n) x} E_{r, i, t-n}\right.$

$D S=E_{r, i, t-}\left(E_{N, i, t /} E_{N, i, t-n}\right) E_{r, i, t-n}$

Keterangan :

EN : Total PDRB Provinsi Sulawesi Utara

Er : Total PDRB Kabupaten Minahasa Selatan

$i \quad:$ Sektor tertentu

$T \quad$ : Tahun

$t-n \quad:$ Tahun Awal

PS : Proportional Shift (Juta Rupiah)

DS : Differential Shift (Juta Rupiah)

3. Analisis Model Rasio Pertumbuhan (MRP)

Analisis Model Rasio Pertumbuhan (MRP) merupakan alat analisis untuk mendapatkan hasil yang dapat mencerminkan sektor potensial dari suatu daerah. Model Rasio Pertumbuhan (MRP) yaitu perbandingan pertumbuhan berdasarkan pada kriteria PDRB suatu kegiatan sektoral baik dalam lingkup yang lebih luas (Provinsi Sulawesi Utara) maupun di Kabupaten Minahasa Selatan. Pendekatan MRP ini juga dibagi menjadi dua (Yusuf, dalam Nisa 2014) yaitu:

1. Rasio Pertumbuhan Wilayah Referensi (RPr)

Rasio pertumbuhan wilayah referensi yaitu membandingkan pertumbuhan masingmasing sektor di Provinsi Sulawesi utara dengan total (PDRB) provinsi sulut. Jika $R P r$ sektor tertentu lebih besar dari 1 maka $R P r$ dikatakan (+) yang berarti pertumbuhan suatu sektor tertentu di Provinsi Sulawesi Utara lebih tinggi dari pertumbuhan PDRB Provinsi Sulawesi Utara. Selain itu, jika $R P r$ lebih kecil dari 1 maka RPr dikatakan (-) yang berarti bahwa pertumbuhan suatu sektor tertentu di Provinsi Sulut lebih rendah dari pertumbuhan PDRB Provinsi Sulawesi Utara.

2. Rasio Pertumbuhan Wilayah Studi (RPs)

Rasio pertumbuhan wilayah studi (RPs) memiliki perbedaan dengan RPr. Rasio Pertumbuhan Wilayah Studi yaitu membandingkan pertumbuhan masing-masing sektor khusus di wilayah studi (Kabupaten Minahasa Selatan) dengan pertumbuhan sektoral di Provins Sulawesi Utara. Jika RPs lebih besar dari 1 maka RPsdikatakan positif (+) yang berarti pertumbuhan sektor tertentu di Kabupaten Minahasa selatan lebih tinggi dari pertumbuhan sektor tertentu Provinsi Sulawesi Utara dan jika RPs lebih kecil dari 1 dikatakan negatif (-) yang berarti bahwa pertumbuhan suatu sektor tertentu ditingkat Kabupaten Minahasa Selatan lebih rendah dari pada pertumbuhan sektor i Provinsi Sulawesi Utara.

Menurut Yusuf (1999) bahwa analisis MRP akan diperoleh nilai riil dan nilai nominal kemudian hasil kombinasi keduanya dapat diperoleh deskripsi sektor ekonomi yang potensial di Kabupaten Minahasa Selatan yang dapat diklasifikasikan menjadi empat bagian yaitu:

a. Klasifikasi Pertama, yaitu nilai $\operatorname{RPr}(+)$ dan $R P s \quad(+)$ berarti sektor tersebut memiliki pertumbuhan yang menonjol baik ditingkat provinsi Sulawesi Utara maupun tingkat 
Kabupaten Minahasa Selatan. Sektor ini disebut sebagai dominan pertumbuhan.

b. Klasifikasi Kedua, yaitu nilai $R P r(+)$ dan $R P s$ $(-)$ berarti sektor tersebut memiliki pertumbuhan yang menonjol ditingkat Provinsi Sulawesi Utara, namun belum menonjol di tingkat Kabupaten Minahasa Selatan.

c. Klasifikasi ketiga, yaitu nilai $R P r(-)$ dan $R P S$ (+) berarti sektor tersebut memiliki pertumbuhan yang tidak menonjol ditingkat Provinsi Sulawesi Utara sementara pada tingkat Kabupaten Minahasa Selatan termasuk menonjol.

d. Klasifikasi keempat, yaitu nilai $\operatorname{RPr}(-)$ dan $R P S(-)$ berarti sektor tersebut memiliki pertumbuhan yang rendah baik di tingkat Kabupaten Minahasa Selatan maupun di tingkat Provinsi Sulawesi Utara.

Rumus (RPr) yaitu ;

$$
R P r=\frac{\Delta E N, i, t / E N, i, t-n}{\Delta E N, t / E N, t-n}
$$

Keterangan :

$R P r$ : Rasio pertumbuhan wilayah referensi (Provinsi Sulut)

$\triangle \mathrm{E}_{\mathrm{N}, \mathrm{i}}$ : PDRB sektor i di Provinsi Sulawesi

Utara

$\Delta \mathrm{E}_{\mathrm{N}}$ : PDRB Total di provinsi Sulawesi Utara

$t \quad:$ tahun

$t-n \quad:$ tahun awal

.Rumus RPs adalah:

$$
R P s=\frac{\Delta E r, i, t / E r, i, t-n}{\Delta E N, i, t / E N, i, t-n}
$$

Keterangan:

RPs = Rasio pertumbuhan wilayah studi (Kabupaten Minahasa Selatan)

$\triangle \mathrm{Er}, \mathrm{i}=\mathrm{PDRB}$ sektor $\mathrm{i}$ di Kabupaten

Minahasa Selatan

$\triangle \mathrm{EN}, \mathrm{i}=$ PDRB sektor i di Provinsi Sulawesi Utara

$T \quad=$ Tahun

$t-n=$ Tahun Awal

\section{HASIL DAN PEMBAHASAN}

\section{Keadaan geografis Kabupaten Minahasa Selatan}

Kabupaten Minahasa Selatan adalah kabupaten yang di mekarkan pada tahun 2003 dengan disahkannya Undang-Undang Nomor 10 Tahun 2003 tentang Pembentukan Kabupaten Minahasa Selatan dan Kota Tomohon di Provinsi Sulawesi Utara, dan ibukota Kabupaten Minahasa Selatan adalah Amurang. Kabupaten Minahasa Selatan terdiri atas 17 kecamatan. Luas wilayah kabupaten minahasa selatan adalah 1.484,47 $\mathrm{km}^{2}$.

\section{Keadaan Perekonomian Kabupaten Minahasa Selatan}

Secara umum pertumbuhan ekonomi Kabupaten Minahasa Selatan terus menerus meningkat dari tahun ke tahun. Hal ini terlihat dari besaran produk domestic regional bruto (PDRB) selama 5 tahun terakhir atas dasar harga konstan pada tahun 2014 sebesar 4.575.164,4 juta rupiah, secara rillekonomi kabupaten minahasa selatan mengalami pertumbuhan sebesar $6,70 \%$ dari tahun sebelumnya. Hal yang sama terjadi di provinisi Sulawesi Utara Secara umum pertumbuhan ekonomi Provinsi Sulawesi Utara terus menerus meningkat dari tahun ke tahun. Hal ini terlihat dari besaran produk domestic regional bruto (PDRB) selama 5 tahun terakhir atas dasar harga konstan pada tahun 2014 sebesar 66.358.764.8. Pada Tabel 1. Struktur ekonomi dapat di artikan sebagai komposisi peranan masing-masing sektor dalam perekonomian baik menurut lapangan usaha maupun pembagian sektoral ke dalam sektor primer, sekunder, dan tersier. Sektor primer merupakan gabungan dari sektor Pertanain, Kehutanan, dan Perikanan, sektor pertambangan dan penggalian. Sektor sekunder merupakan gabungan dari sektor Industri Pengolahan, Sektor Pengadaan Listrik dan Gas, Sektor Pengadaan Air, Pengelolaan Sampah, Limbah dan Daur Ulang dan Sektor Konstruksi. Sektor tersier merupakan gabungan dari sektor Perdagangan Besar \& Eceran: Reparasi Mobil dan Sepeda Motor, Sektor Transportasi dan Pergudangan, sektor Penyediaan Akomodasi dan Makan Minum, Sektor Informasi dan Komunikasi, Sektor Jasa Keuangan dan Asuransi, Sektor Real Estate, Sektor Jasa Perusahaan, sektor Administrasi, Pemerintahan, 
Pertahanan dan Jaminan Sosial Wajib, Sektor Jasa Pendidikan, sektor Jasa Kesehatan dan Kegiatan Sosial, Sektor Jasa Lainnya. Di lihat dari 3 sektor utama, kontribusi sektor primer pada tahun 2014 sebesar $43.64 \%$ sementara itu sektor sekunder pada tahun 2014 sebesar $26.09 \%$ dan sektor tersier pada tahun 2014 sebesar $30.17 \%$. hal ini menunjukan bahwa sektor primer masih mendomonasi di kabupaten Minahasa Selatan.

\section{Analisis Potensi Pertumbuhan Sektor Ekonomi}

\section{Analisis LQ}

Analisi

kinerja sektor-sektor perekonomian di kabupaten minahasa selatan dapat di hitung menggunakan analisis LQ.Analisis LQ digunakan untuk menetukan sektor basis di Kabupaten Minahasa Selatan. Berdasarkan Tabel 2. Kabupaten Minahasa Selatan memiliki 4 sektor basis, sektor tersebut yaitu sektor pertambangan dan penggalian dengan indeks LQ sebesar 1.83 sektor pertambangan dan penggalian memiliki kekuatan yang cukup baik karena adanya potensi bahan galian batuan yang terdapat di sungai di masing-masing kecamatan yakni tatapaan, tumpaan, amurang timur, amurang, amurang barat, tompaso baru dan kecamatan tenga. Kemudian tambang emas, belerang, kaolin, lempung, batu kapur, pasir besi yang di kelola oleh perusahaan juga dinas terkait. Juga adanya perusahaan yang menguasai pertambangan yang sudah mendapat izin usaha pertambangan dengan komoditas yakni emas dan pasir besi.

Sektor basis kedua dengan LQ sebesa 1.61 adalah sektor pertanian, kehutanan, dan perikanan. Hal ini di karenakan oleh sub sektornya seperti tanaman pangan. Penyebaran produksi padi ( padi sawah dan ladang ) di Kabupaten Minahasa Selatan menunjukan konsentrasi produksi padi pada kecamatan ranoyapo, tompaso baru dan maesaan. kemudian tanaman hortikultura, produktivitas tanaman sayuran dan buah-buahan seperti pisang dan rambutan menghasilkan produksi terbanyak. Sub sektor perkebunan, produksi tanaman perkebunan terdiri dari kelapa, cengkih, pala, kakao, kopi, aren, casiavera. Produksi tanaman perkebunan di dominasi oleh tanaman kelapa. Dan sub sektor kehutanan terbagi menjadi hutan cagar alam, hutan lindung, hutan bakau, hutan produksi, hutan produksi terbatas, dan hutan suaka margasatwa. Sektor yang juga merupakan sektor basis adalah sektor industri pengolahan dengan nilai LQ sebesar 1.14 usaha di kabupaten minahasa selatan di bagi menjadi usaha mikro, usaha kecil, usaha menengah.Setiap kecamatan di kabupaten minahasa selatan memiliki usaha seperti perdagangan, industri non pertanian, industri pertanian dan berbagai jasa.kecamatan amurang merupakan titik terbesar kegiatan usaha yang di lakukan oleh masyarakat. Dan kontribusi terbesar padasektor industri pengolahan adalah sub sektor makan dan minum. Kemudian sektor konstruksi memiliki nilai LQ sebesar 1.07 pertumbuhan sektor konstruksi di dorong oleh berbagai proyek pembangunan yang di lakukan oleh pihak pemerintah, swasta, maupun rumah tangga. Beberapa kegiatan pembangunan pendorong pertumbuhan kategori konstruksi antara lain perbaikan infrastruktur, pembangunan, rekonstruksi/ perbaikan dan pelebaranbeberapa jalan, revitalisasi dan penggantian beberapa jembatan, pembangunan gedung dan perbaikan gedung pemerintah dan pembangunan gedung milik swasta seperti hotel dan pertokoan. Sektor yang merupakan sektor non basis selama periode tahun 2014 terdapat 13 sektor yaitu sektor pengadaan listrik dan gas dengan nilai LQ 0.74 ; sektor pengadaan air, pengelolaan sampah, limbah dan daur ulang dengan nilai LQ 0.48 ; sektor perdagangan besar dan eceran : reparasi mobil dan sepeda motor dengan nilai LQ 0.61 ; sektor transportasi dan pergudangan memiliki nilai LQ 0.86 ; sektor penyediaan akomodasi dan makan minum memiliki nilai LQ 0.17 ; sektor informasi dan komunikasi memiliki nilai LQ 0.40 ; sektor jasa keuangan dan asuransi memiliki nilai LQ 0.26 ; sektor real estate memiliki nilai LQ 0.90; sektor administrasi, pemerintahan, pertahanan dan jaminan social wajib memiliki nilai LQ 0.58 ; sektor jasa pendididkan memiliki nilai LQ 0.46 ; sektor jasa kesehatan dan kegiatan social memiliki nilai LQ 0.80; sektor jasa lainnya memiliki nilai LQ 0.24. walaupun sektor basis merupakan sektor potensial untuk di kembangkan dan untuk memacu pertumbuhan ekonomi kabupaten minahasa selatan, sektor nonbasis harus di kembangkan untuk menjadi sektor basis baru, di tunjang dengan sektor basis yang telah ada. 
Tabel 1. Kontribusi Sektor-Sektor Perekonomian Terhadap PDRB Kabupaten Minahasa Selatan Menurut Lapangan Usaha Tahun 2014

\begin{tabular}{llc}
\hline No & Lapangan Usaha & $\mathbf{2 0 1 4}$ \\
\hline 1. & Pertanian,Kehutanan \& Perikanan & 34.72 \\
2 & Pertambangan dan Penggalian & 8.92 \\
3 & Industri Pengolahan & 12.32 \\
4 & Pengadaan Listrik dan Gas & 0.07 \\
5 & Pengadaan Air, Pengelolaan Sampah, Limbah dan Daur Ulang & 0.06 \\
6 & Konstruksi & 13.64 \\
7 & Perdagangan Besar \& Eceran: Reparasi Mobil dan Sepeda Motor & 7.87 \\
8 & Transportasi dan Pergudangan & 7.31 \\
9 & Penyediaan Akomodasi dan Makan Minum & 0.36 \\
10 & Informasi dan Komunikasi & 1.79 \\
11 & Jasa Keuangan dan Asuransi & 0.95 \\
12 & Real Estate & 3.28 \\
13 & Jasa Perusahaan & 0.01 \\
14 & Administrasi, Pemerintahan, Pertahanan dan Jaminan Sosial Wajib & 4.08 \\
15 & Jasa Pendidikan & 1.14 \\
16 & Jasa Kesehatan dan Kegiatan Sosial & 3.00 \\
17 & Jasa Lainnya & 0.38 \\
\hline Suma & : BPS Minasa Selan 2016(Otaha) & \\
\hline
\end{tabular}

Sumber : BPS Minahasa Selatan 2016 (Olahan)

Tabel 2. Nilai LQ Masing - Masing Sektor di Kabupaten Minahasa Selatan Tahun 2014

\begin{tabular}{llc}
\hline No & \multicolumn{1}{c}{ Lapangan Usaha } & 2014 \\
\hline 1 & Pertanain, Kehutanan, Dan Perikanan & 1.61 \\
2 & pertambangan dan penggalian & 1.83 \\
& & 1.14 \\
3 & industri pengolahan & 0.74 \\
4 & pengadaan listrik dan gas & 0.48 \\
5 & pengadaan air, pengelolaan sampah, limbah dan daur ulang & 1.07 \\
6 & Konstruksi & 0.61 \\
7 & perdagangan besar besar dan eceran ; reparasi mobil dan sepeda motor & 0.86 \\
8 & transportasi dan pergudangan & 0.17 \\
9 & penyediaan akomodasi dan makan minum & 0.40 \\
10 & informasi dan komunikasi & 0.26 \\
11 & jasa keuangan dan asuransi & 0.90 \\
12 & Real Estate & 0.19 \\
13 & Jasa Perusahaan & 0.58 \\
14 & Administrasi Pemerintahan, Pertahanan dan Jaminal Social Wajib & 0.46 \\
15 & Jasa Pendidikian & 0.80 \\
16 & Jasa Kesehatan dan Kegiatan Social & 0.24 \\
17 & Jasa Lainnya & \\
\hline
\end{tabular}




\section{Analisis Shift Share}

Analisis ini bertujuan untuk menentukan kinerja atau produktivitas kerja perekonomian daerah dengan membandingkannya dengan daerah yang lebih besar. Dalam penelitian ini di gunakan PDRB untuk menguraikan pertumbuhan ekonomi kabupaten minahasa selatan. Berdasarkan Tabel 3. hasil analisis menunjukan bahwa komponen PS memberikan pengaruh negatif bagi perkembangan perekonomian Kabupaten Minahasa Selatan yaitu sebesar -97 miliar. Nilai negatif mengindikasikan komposisi sektor pada PDRB Kabupaten Minahasa Selatan cenderung mengarah pada perekonomian yang tumbuh relatif lambat. Pada Tabel 3. dapat di lihat sektor-sektor yang mendapat pengaruh bauran industri yaitu sektor pertambangan dan penggalian, sektor pengadaan listrik dan gas, sektor Konstruksi, sektor perdagangan besar besar dan eceran ; reparasi mobil dan sepeda motor, sektor transportasi dan pergudangan, sektor penyediaan akomodasi dan makan minum, sektor informasi dan komunikasi, sektor jasa keuangan dan asuransi, sektor Real Estate, sektor Jasa Perusahaan, sektor Jasa Kesehatan dan Kegiatan Social, sektor Jasa Lainnya. Untuk komponen DS menghasilakn nilai keunggulan kompetitif sebesar -98 miliar. Nilai ini mengindikasikan bahwa keunggulan kompetitif yang di hasilkan akan mengurangi perkembangan perekonomian Kabupaten Minahasa Selatan sama sekali tidak kompetitif. Hal ini meskipun secara agregat nilainnya negative tetapi terdapat sektor yang mempunyai nilai positif yaitu sektor industri pengolahan, sektor Konstruksi, sektor Administrasi Pemerintahan, sektor Pertahanan dan Jaminal Social Wajib dan sektor Jasa Kesehatan dan Kegiatan Social.

\section{Analisi Model Rasio Pertumbuhan (MRP)}

Analisis ini dilakukan untuk melihat deskripsi kegiatan ekonomi, terutama struktur ekonomi Kabupaten Minahasa Selatan yang lebih menekankan pada kriteria pertumbuhan. Analisis Model Rasio Pertumbuhan (MRP) merupakan kegiatan membandingkan pertumbuhan suatu kegiatan baik dalam skala yang lebih kecil maupun dalam skala yang lebih luas. Berdasarkan analisis MRP pada Tabel 3 terdapat 2 sektor yang menonjol baik di tingkat provinsi Sulawesi Utara maupun Kabupaten Minahasa Selatan yakni sektor konstruksi, dan sektor jasa kesehatan dan kegiatan sosial.
Sektor konstruksi masuk pada klasifikasi satu hal ini berarti sektor konstruksi memiliki pertumbuhan yang menonjol di tingkat Kabupaten Minahasa Selatan maupun tingkat Provinsi Sulut.hal ini di dorong berbagai proyek pembangunan yang di lakukan oleh pihak pemerintah, swasta, maupun rumah tangga. Beberapa kegiatan pembangunan pendorong pertumbuhan kategori konstruksi antara lain perbaikan infrastruktur, pembangunan rekonstruksi, atau perbaikan dan pelebaran beberapa jalan, revitalisasi dan penggantian beberapa jembatan, pembangunan dan perbaikan gedung pemerintahan dan pembangunan gedung milik swasta seperti hotel dan pertokoan. Sektor jasa kesehatan dan kegiatan sosial masuk pada klasifikasi satu hal ini berarti Sektor jasa kesehatan dan kegiatan sosial memiliki pertumbuhan yang menonjol baik tingkat kabupaten minahasa selatan maupun provinsi Sulawesi utara. hal ini di dorong oleh kegiatan jasa kesehatan juga gerakan aktivitas partai politik dalam rangka pemilu legislatif dan pemilu presiden.

Kemudian sektor yang masuk klasifikasi dua ada 10 sektor yakni sektor pertambangan dan penggalian, sektor pengadaan listrik dan gas, sektor perdagangan besar dan eceran : reparasi mobil dan sepeda motor, sektor transportasi dan pergudangan, sektor penyediaan akomodasi makan dan minum, sektor informasi dan komunikasi, sektor jasa keuangan dan asuransi, sektor real estate, sektor jasa perusahaan, dan sektor jasa lainnya. Sektor - sektor ini memiliki pertumbuhan yang menonjol di Sulawesi utara, tapi tidak menonjol di kabupaten minahasa selatan. Sektor yang masuk pada klasifikasi tiga terdapat 2 sektor yakni sektor industri pengolahan dan sektor administrasi, pemerintahan, pertahanan, jaminan sosial wajib. Kedua sektor ini tidak menonjol di Provinsi Sulawesi Utara tetapi menonjol di tingkat kabupaten minahasa selatan. Sektor ini diharapkan akan potensial peranannya dalam memberikan kontribusi pertumbuhan di provinsi sebab sektor ini merupakan sektor potensial yang dapat di kembangkan di Kabupaten Minahasa Selatan. Untuk sektor industri pengolahan di tingkat Kabupaten Minahasa Selatan selama periode 2014 cenderung bertumbuh stabil. Sub sektor industry pengolahan yang mencatatkan pertumbuhan terbesar adalah makanan dan minuman sedangkan untuk sektor sektor administrasi, pemerintahan, pertahanan, 
jaminan sosial wajib mengalami pertumbuhan dengan peningkatan belanja gaji pegawai yang naik setiap tahunnya serta meningkatknya jumlah PNS yang masuk dari jalur honorer dan juga tingginya belanja modal pemerintah di tahun 2014. Sektor yang masuk pada klasifikasi empat terdapat 3sektor yakni sektor pertanian, seiring

kehutanan, dan perikanan, sektor pengadaan air, pengadaan sampah, limbah dan daur ulang, dan yang terakhir adalah sektor jasa pendidikan hal berarti baik di tingkat provinsi maupun kabupaten mengalami pertumbuhan yang rendah.

Tabel 3. Analisis Shift share Masing- masing sektor di Kabupaten Minahasa Selatan Tahun 2014

\begin{tabular}{llrr}
\hline No & \multicolumn{1}{c}{ Lapangan Usaha } & PS & DS \\
\hline 1 & Pertanain, Kehutanan, Dan Perikanan & -172628 & -20894 \\
2 & pertambangan dan penggalian & 6368.052 & -25609.8 \\
3 & industri pengolahan & -13461.7 & 51471.14 \\
4 & pengadaan listrik dan gas & 763.5691 & -1309.03 \\
5 & pengadaan air, pengelolaan sampah, limbah dan daur & & \\
& ulang & -56.679 & -244.04 \\
6 & Konstruksi & 23435.45 & 13889.01 \\
7 & perdagangan besar besar dan eceran ; reparasi mobil dan & & \\
& sepeda motor & 24311.22 & -24871.9 \\
8 & transportasi dan pergudangan & 14122.71 & -6550.21 \\
9 & penyediaan akomodasi dan makan minum & 1222.532 & -878.69 \\
10 & informasi dan komunikasi & 6235.349 & -1970.98 \\
11 & jasa keuangan dan asuransi & 2170.209 & -3368.03 \\
12 & Real Estate & 8073.677 & -7582.86 \\
13 & Jasa Perusahaan & 49.74711 & -34.16 \\
14 & Administrasi Pemerintahan, Pertahanan dan Jaminal & & \\
& Social Wajib & -2239 & 9670.46 \\
15 & Jasa Pendidikian & -1773.41 & -725.71 \\
16 & Jasa Kesehatan dan Kegiatan Social & 5082.584 & 9657.92 \\
17 & Jasa Lainnya & 415.2317 & -471.51 \\
\hline & Jumlah & -97908.5 & -9822.38 \\
\hline
\end{tabular}

\section{KESIMPULAN DAN SARAN}

\section{Kesimpulan}

1. Sektor basis di Kabupaten Minahasa Selatan adalah sektor pertanian, sektor pertambangan dan penggalian, sektor industri pengolahan, sektor konstruksi merupakan sektor basis yang dominan di Kabupaten Minahasa Selatan.

2. Kabupaten Minahasa Selatan berada pada posisi perekonomian yang tumbuh relatif lambat dan tidak memiliki keunggulan kompetitif. Sektor yang menonjol baik di kabupaten Minahasa Selatan maupun di Provinsi Sulawesi Utara adalah sektor konstruksi dan sektor jasa kesehatan dan kegiatan sosial dan sektor yang tidak menonjol di provinsi Sulawesi utara tetapi menonjol di Kabupaten Minahasa Selatan yakni sektor industri pengolahan, dan sektor administrasi, pemerintahan, pertahanan, jaminan sosial wajib.

Saran
Pemerintah di Kabupaten Minahasa
Selatan perlu menetapkan kebijakan
pembangunan dengan prioritas sektor unggulan/
basis di masing-masing sektor dengan tetap
memperhatikan sektor non basi secara
proporsional. Serta perlu melakukan revitalisasi
semua sektor dimulai sektor yang memiliki nilai
LQ $>$ kemudian LQ 1 serta memacu
peningkatan produktifitas dan profesionalisme
dalam mengelola sektor-sektor potensial agar
mempunyai keunggulan kompetitif dan
komperatif untuk meningkatkan pedapatan daerah
Kabupaten Minahasa Selatan.

\section{Saran}

Selatan perlu menetapkan kebijakan pembangunan dengan prioritas sektor unggulan/ basis di masing-masing sektor dengan tetap memperhatikan sektor non basis secara proporsional. Serta perlu melakukan revitalisasi semua sektor dimulai sektor yang memiliki nilai LQ > 1 kemudian LQ $<1$ serta memacu peningkatan produktifitas dan profesionalisme dalam mengelola sektor-sektor potensial agar Kabupaten Minahasa Selatan. 


\begin{tabular}{|c|c|c|c|c|}
\hline \multicolumn{2}{|c|}{ Tabel 4.} & \multirow{3}{*}{$\begin{array}{c}\mathbf{R p r} \\
0.90\end{array}$} & \multirow{3}{*}{$\begin{array}{l}\text { Rps } \\
0.98\end{array}$} & \multirow{3}{*}{$\begin{array}{c}\text { nahasa Selatan } \\
\text { Klasifikasi } \\
\text { Empat }\end{array}$} \\
\hline No & Lapangan Usaha & & & \\
\hline 1 & Pertanian,Kehutanan dan Perikanan & & & \\
\hline 2 & Pertambangan dan Penggalian & 1.01 & 0.94 & Dua \\
\hline 3 & Industri Pengolahan & 0.97 & 1.10 & Tiga \\
\hline 4 & Pengadaan Listrik dan Gas & 1.19 & 0.73 & Dua \\
\hline 5 & $\begin{array}{l}\text { Pengadaan Air, Pengelolaan } \\
\text { Limbah dan Daur Ulang }\end{array}$ & 0.98 & 0.92 & Empat \\
\hline 6 & Konstruksi & 1.04 & 1.02 & Satu \\
\hline 7 & $\begin{array}{l}\text { Perdagangan Besar \& Eceran: Reparasi } \\
\text { Mobil dan Sepeda Motor }\end{array}$ & 1.07 & 0.93 & Dua \\
\hline 8 & Transportasi dan Pergudangan & 1.04 & 0.98 & Dua \\
\hline 9 & Penyediaan Akomodasi dan Makan Minum & 1.07 & 0.95 & Dua \\
\hline 10 & Informasi dan Komunikasi & 1.08 & 0.97 & Dua \\
\hline 11 & Jasa Keuangan dan Asuransi & 1.05 & 0.92 & Dua \\
\hline 12 & Real Estate & 1.05 & 0.95 & Dua \\
\hline 13 & Jasa Perusahaan & 1.07 & 0.95 & Dua \\
\hline 14 & $\begin{array}{l}\text { Administrasi, Pemerintahan, Pertahanan, } \\
\text { Jaminan Sosial Wajib }\end{array}$ & 0.99 & 1.05 & Tiga \\
\hline 15 & Jasa Pendidikan & 0.97 & 0.98 & Empat \\
\hline 16 & Jasa Kesehatan dan Kegiatan Sosial & 1.04 & 1.07 & Satu \\
\hline 17 & Jasa Lainnya & 1.02 & 0.97 & Dua \\
\hline
\end{tabular}

\section{DAFTAR PUSTAKA}

Budiman, A. 1996.Teory Pembangunan Dunia Ketiga. PT Gramedia Pustaka Utama, Jakarta

BPS. 2015. Sulawesi Utara Dalam Angka 2015. Badan Pusat Statistik Provinsi Sulawesi Utara, Manado

BPS. 2015. Minahasa Selatan Dalam Angka 2014. Badan Pusat Statistik Kabupaten Minahasa Minahasa Selatan,Minahasa Selatan.

Herlina Rahman Dan Warsito "Pendapatan Asli Daerah"

Www.Negarahukum.Com/Hukum/Pendapatan aslidaerah.Html 10maret 2016

Lapadjawa. 2015. Peranan Sektor Pertanian Terhadap Kabupaten Bolaang Mongondow Timur. Fakultas Pertanian UNSRAT, Manado. Skripsi

Masias, 2013. Menghitung Potensi Pajak Hotel Di Kota Kediri. Fakultas Ekonomi Dan Bisnis, Makasar. Skripsi

Nisa, 2014. Analisis Potensi Ekonomidan Pengembangan Wilayah Kabupaten Lebak Provinsi Banten. Fakultas Ekonomi UNDIP. Semarang. Skripsi
Putra, N. 2013. Analisis Potensi Ekonomi Kabupaten dan Kota di Provinsi DIY. Fakultas Ekonomi dan Bisnis, Universitas Islam Negeri Syarif Hidayatullah, Jakarta skripsi.

Sengka, C. 2015. Analisis Tenaga Kerja Sektoral Di Kota Tomohon. Fakultas Pertanian UNSRAT, Manado. Skripsi

Soeparmoko, 2002.Perencanaan Ekonomi Wilayah . Citra Pustaka, Yogyakarta

Sukirno, S. 2004. Makro Ekonomi, Pengantar Dan Teori, Raja Grafindo Persada. Jakarta

Suryana. Drs. 2000 .Ekonomi Pembangunan Problematika Dan Pendekatan Salemba Empat, Jakarta.

Tarigan. 2005. Ekonomi Regional : Teori Dan Aplikasi . Bumi Aksara, Jakarta

Yusuf, M. 1999. Ekonomi Dan Keuangan Indonesia Volume XIVII Nomor 2. UNPAD. Bandung

Zulaechah, 2011. Analisis Pengembangan Kota Magelang Sebagai Pusat Pertumbuhan Kawasan Purwomangun Jawa Tengah. Fakultas Ekonomi Dan Bisnis UNDIP, Semarang Skripsi. 